\title{
Perceptions of Communication and Respect Among Coworkers: a Comparison of Employees with and Without Experience in Long-Term Care Environments
}

\author{
Lisa E. $\operatorname{Cox}^{1}$ - Felicia Mainiero ${ }^{2}$
}

Published online: 14 October 2017

(C) Springer International Publishing AG 2017

\begin{abstract}
The aim of this study was to evaluate how the work experiences of employees in long-term care affected their perceptions and levels of respect and communication. Content considers the effects of professional and non-professional long-term care (LTC) staff's previous work experience, training, and supervision. The notion of hierarchy is raised in the context of its relationship to human rights, because where human right-based care helps to fulfill the humanity of people, the outcome tends to benefit both service users and care providers. As LTC environments continue to expand and reform, they employ a wide range of professional and nonprofessional staff who have varied educational levels, skill sets, and job responsibilities. Staff burnout and high turnover rates concern LTC administrators and federal and state policies do not require much training or continuing education for certified nursing assistants and other non-professional staff. Relationship issues and experience are important considerations because they connect to staff retention and quality patient care. Herein, a sample of 119 LTC employees was divided into two groups, those with prior LTC experience and those without any prior LTC work experience. Four research questions were tested and limitations and implications for future research are discussed. Findings revealed differences between the two groups; employees who had prior LTC experience
\end{abstract}

Lisa E. Cox

Lisa.Cox@stockton.edu

Felicia Mainiero

mainier1@go.stockton.edu

1 Stockton University, 101 Vera King Farris Dr, Galloway, NJ 08205, USA

21699 Wynnewood Dr, Vineland, NJ 08361, USA perceived higher levels of respect toward residents and toward each other than those employees with no prior experience.

Keywords Coworker satisfaction · Communication · Helpfulness · Respect · Training $\cdot$ Long-term care experience

Long-term care is one of the largest health care providers in the USA serving the aging US population (Nilsson and Engstrom 2015; Sullivan 2016). While there are federal and state requirements on how much training and annual continuing education some staff must complete, LTC administrators in the USA require far less education and training than countries like Sweden, Denmark, and the Netherlands (Han et al. 2014; Nilsson and Engstrom 2015). Staff who receive training of any kind to work in LTC settings and have prior experience tend to be much better-rounded employees, who will be equipped to meet the needs of older adult residents (Nilsson and Engstrom 2015). Because job satisfaction has been linked to turnover rates in LTC, giving more attention to training and relationships may improve employee satisfaction and ultimately reduce staff turnover and improve resident care.

As the US population ages, many formerly independent individuals find that they are in need of long-term care. Insofar as terminology, LTC facilities, include nursing homes, assisted living facilities, residential care, and long-term care homes (Squires et al. 2015). In 2013, the daily average number of people residing in LTC facilities was 1,383,700 according to the Centers for Disease Control (CDC) as cited in Bowman and Forbes (2015). While some care is provided in intermediate or skilled-level nursing homes, a majority of care is now provided in the home-like environments of assisted living facilities. In the USA, LTC facilities, such as nursing homes, provide 24-hour medical care to older adults outside of a hospital setting (Squires et al. 2015). Nursing home residents 
are dependent on multidisciplinary staff for their care and experience varying levels of care. Assisted living facilities are defined as non-medical, community-based, residential settings that provide housing, food services, one or more personal services, and watchful oversight to frail elders. This article uses the general term LTC facility.

To ensure older adults receive quality care, committed, experienced, communicative, and respectful personnel are required. Each employee working in a LTC facility plays a pivotal role in caring for older adult residents, maintaining the physical environment, and fostering a positive emotional working environment. Additionally, administrators, professional and non-professional staff, are responsible for treating each other as respectfully and courteously as they treat the residents.

Occupational satisfaction is affected by teamwork, engagement in work, performance, commitment, and selfdetermination (Squires et al. 2015). For example, low job satisfaction is linked with higher rates of turnover among LTC staff, which results in an insufficient quality of resident care (Chu et al. 2014; Rai 2012). Unfortunately, research on the perceptions of staff in LTC facilities is in its infancy. In response to the need for more research on working conditions (e.g., training and relationships) in LTC facilities, this study reports findings from a cross-sectional, descriptive survey designed to elicit perceptions of employee satisfaction with communication, helpfulness, and respect, shown to both workers and residents. Previously, major research on communication, helpfulness, and respect in LTC facilities has been limited to specific disciplines such as registered nurses (McGilton et al. 2014), nurses and physicians, or certified nursing assistants (Rai 2010). Because a positive work environment includes interactions among all individuals in the environment, this study included all employees working in the LTC facility. The staff was divided into two groups, those who had prior LTC experience working with older adults and those who were working in LTC with older adults for the first time. The independent variable of prior work experience was defined unconventionally to capture staff that had already chosen to leave one facility versus those who had not, so it was simply measured as any length of time at a prior LTC facility.

\section{Literature Review}

\section{Employees of LTC Facilities}

Every day, older adults living in LTC facilities interact with multiple service personnel. Nursing roles are perhaps the most crucial. In LTC facilities, these roles include, registered nurses $(\mathrm{RN})$, licensed practical nurses (LPN), and certified nursing assistants (CNA). The main functions of nurses and CNAs are to provide direct hands on care to residents. Social workers, or case managers, are also employed in LTC facilities. Social workers in LTC provide mental health counseling, care planning, participate in multidisciplinary team meetings, coordinate decision-making and transition processes, as well as advocate, case manage, and support families (Koenig et al. 2011). In addition, LTC facilities employ non-professionals who do not provide direct hands care yet play a pivotal role in ensuring resident needs are met and the physical environment is appealing. Examples of staff include nutritionist and dining service staff, housekeeping, environmental services, marketers, and administrators. All these staff members have perceptions of residents that are shaped by the limited interactions they have. Maintenance and food service staff may have no real formal education or training to enhance competence. Even untrained teens volunteer in LTC settings and interact with staff and residents. Clashes in professional or personal values with other workers' beliefs may contribute to job dissatisfaction and employee turnover (Chu et al. 2014).

LTC facilities are noted for a high employee turnover rate and deficits across all levels of care providers (Squires et al. 2015). A 1-year turnover rate has been recorded as high as $55.4 \%$ for $\mathrm{RNs}$ and $85.5 \%$ for LPNs working in LTC facilities. Turnover rates for LTC settings have been documented as high as $55.4 \%$ for registered nurses and $85.5 \%$ for licensed practical nurses over a 1-year period (Chu et al. 2014). Several studies concerning turnover rates in LTC facilities include data on nurses, gerontological social workers, direct care staff, hospice staff, and other nursing staff, however, there is little data regarding the rate of turnover among ancillary staff (Rai 2010). Literature reveals that when the turnover rate is high, there is a decline in the quality of care given by caregivers and other staff (Chu et al. 2014).

Many reasons can account for employee turnover in facilities. These reasons include personal and professional stressors, lack of career development opportunities, high supervisory turnover, absence of empowerment, insufficient staffing and resources, low employment satisfaction, lack of supervisor support, and emotional exhaustion (Chu et al. 2014; McGilton et al. 2014).

\section{Education and Training of Employees}

Direct care staff are responsible for assisting with many of the activities of daily living (ADL), however, those positions differ greatly and include housekeepers, nursing aides, nurses, social workers, dietary aides, and activity staff (Colón-Emeric et al. 2016; McGilton et al. 2014). Therefore, employees of LTC facilities have diverse educational backgrounds. Administrators, RNs, and social workers require college degrees. Others, such as CNAs, require only a high school 
degree and discipline specific training. Still others, such as grounds people and dietary personnel, may have a high school education or less, yet still possess adequate enough skills for their particular job. Additionally, a large portion of staff may have little or no training in geriatrics or disabilities before they begin work in LTC facilities and often do not receive any or adequate training, as in other countries, once they are employed in the facilities (Sullivan 2016). Many LTC facilities are implementing their own training programs for staff within the orientation. For example, one of Genesis Health Care's locations incorporated a 4-8-week orientation specific to training nurses based on their background, skills, and experience. This orientation has dramatically reduced turnover rates and helped save money (Barbarotta 2010). Nonprofessional employees who often lack continued education, formal certifications or qualifications, and supervision provide 70 to $80 \%$ of direct care in LTC facilities (Squires et al. 2015). Furthermore, changes in the welfare system resulted in former recipients obtaining work in the service industry without sufficient training (DeBord et al. 2000). Thus, many long-term care facilities may have unqualified or poorly qualified staff because many positions do not have an educational requirement (Sullivan 2016; Squires et al. 2015). In the USA, there are federally regulated minimum training requirements (75 hours of initial training and 12 hours of continuing education annually) and each state has the authority to require more training and continuing education hours. Additional training has been associated with improved LTC quality indicators (Han et al. 2014).

\section{Communication Among Employees}

The coordination of interdisciplinary practice should be coordinated by supervisors on a large scale level. However, employees should also be prepared enough, before entering the long-term care field, to effectively communicate across multiple disciplines and professions. A foundation of positive interaction in LTC staff is teamwork. Teamwork stems from good interpersonal and communication skills and these are vital for employees who work in LTC facilities (McGilton et al. 2014). However, even in the most organized teams, multiple interpersonal and communication problems emerge (Fulmer 2016). The problems stem from workers focusing on their own positions and responsibilities, without considering the total resident picture (McGilton et al. 2014). Assessment and care planning are integral to resident well-being. Good assessment and care planning includes effective and productive two-way communication between professionals, staff, and administrators (Fulmer 2016). In the fast-paced environment of a LTC facility, conversation is generally functional (e.g., when nurses give charge reports) and fragmented. For example, staff members converse with coworkers to impart information regarding tasks that require completion. This type of functional conversation may work very efficiently in the business sector, however similar conversation can be detrimental in the human service environment. In addition, fragmented communication leads to confusion and frustration among staff and residents (Squires et al. 2015).

Communication is one way in which individuals gain approval or disapproval from their supervisors and coworkers. When communication is clear and precise, mistakes are less likely to occur. Supervisors need to display competence in their knowledge by imparting information in a positive and authoritative manner to those they supervise. Because effective supervision is conducive to a positive work environment, it is important for supervisors to possess positive "people skills". In a study of job satisfaction among health care workers, communication with supervisors was identified as a top component of worker satisfaction (Chu et al. 2014). In fact, Chu et al. found that extrinsic traits, such as the quality of the supervisor's style, were more important than traits individual workers brought with them to the work force in determining worker satisfaction.

Coworker relationships and communication are another aspect of job satisfaction. The American Geriatric Society has put forth a strong position statement that clearly lays out the mandate for interdisciplinary teams for quality care of older adults (Fulmer 2016). Teams and team care are integral to caring for older people, yet insufficient evidence exists as to how to best prepare new clinicians for team care and how to determine the right "dose" of team in any given clinical caregiving situation (Fulmer 2016). Effective coworker communication is one of the keys to retaining staff and ensuring that residents' needs are met (McGilton et al. 2014). Effective communication between coworkers results in increased levels of understanding and cooperative endeavors between disciplines (Tourangeau et al. 2010). The importance of positive communication is that it denotes that an individual respects another individual (McGilton et al. 2014). Problems frequently begin when the opposite occurs. One study found that the poorest teamwork and communication skills have been found among certified nursing aides (Tourangeau et al. 2010). Aspects of hierarchy influence communication, especially among nursing staff and physicians (Fulmer 2016). Communication also breaks down when various disciplines conduct their work without paying attention to the work of other disciplines (McGilton et al. 2014). Often people who are employed on a temporary or part-time basis experience less communication, especially positive and consistent communication, with their coworkers (Bowman and Forbes 2015).

\section{Helpfulness of Coworkers}

Helping others when they need help is the principle behind LTC staff satisfaction. Mutual understanding, nurturing, support, and organizational ability are main characteristics needed 
by workers in LTC facilities (McGilton et al. 2014). People who possess these traits represent those who are most likely to help their coworkers (McGilton et al. 2014). These traits are especially helpful because LTC facilities are understaffed and existing workers are called upon to perform duties outside of their area of expertise (Lockey 1999). Working conditions often improve when employees display a team spirit and help their coworkers. Additionally, coworker cooperation has been identified as a factor that reduces staff turnover in LTC facilities because cooperation helps staff feel connected (ColónEmeric et al. 2016).

\section{Human Rights and Social Justice Relate to Staff Competence, Communication, Respect}

Older adults have a right to expect adequate staff attention and respect (Blakemore 2013). In addition, Staub-Bernasconi (2012), reminds readers that the value base of human rights refers to human dignity and that human rights differ from other rights. The human rights of older adults, as outlined in the Declaration on the Rights of Older Persons and proposals for a Convention on the Rights of Older Persons, have many implications for long-term care (Butler 2002). One UK researcher has cited a 2009 Equality and Human Rights Commission Inquiry that highlighted the need for a "human rights approach" to encourage participation by service users in service planning and delivery, increasing their autonomy, enhancing self-respect, and building better relationships (YatesBolton 2010, p. 26). Essentially, the enquiry illustrates how courageous and strong leadership blended with development and training on human rights can result in positive outcomes for service users and staff morale.

The notion of social justice may be applied to areas of health care and LTC, especially to issues of access, diagnosis, and provision of services. In the context of health disparities, social justice refers to minimizing social and economic conditions that may harm people's health. Poverty, being uninsured, inadequate education, and limited available medical care are all factors related to social injustice that require consideration by LTC employees. By understanding a group's belief systems, values, and styles of behaving and thinking researchers, care providers, and policymakers may become more equipped to recognize the cultural influences that serve as barriers and facilitators to eliminating health disparities (Dilworth-Anderson et al. 2012).

\section{Respect by Coworkers}

Closely linked to helping others is the perception of respect from coworkers. Psychosocial well-being promotes worker feelings of being respected in their position (Bond and Fiedler 1999). The literature reveals many employees feel as though coworkers and managers do not respect them. Several studies have identified a hierarchy that contributes to workers' feeling that they are being treated disrespectfully (Cadogan et al. 1999; Fulmer 2016; Rai 2012). In a qualitative study of nurses, Pope et al. (1998), reported turnover among registered nurses (RNs) often stems from their belief that other nurses disrespect them. The turnover of CNAs has also been related to their feelings that they are not treated with respect by the RN staff (McGilton et al. 2014; Tourangeau et al. 2010).

Quality of communication is also associated with whether people feel respected by other workers. Cadogan et al. (1999) studied 59 registered nurses (RNs) and 47 physicians and reported a breakdown in communication between the professions. Physicians believed that the communication from nurses was professional and respectful; however, nurses did not believe the communication from physicians was professional and respectful. It appears that there is a hierarchy of professionals that results in those higher on the list communicating that they know best rather than recognizing those under them are also professionals who contributed by way of a different but no less important discipline. The hierarchical structure leads to some workers' feeling that people in different disciplines communicate in manners that are disrespectful to them. In fact, Cadogan et al. (1999) and Dilworth-Anderson et al. (2012) reported that high turnover among all LTC employees is related to ongoing differences in professional cultures and social structures.

Throughout the literature review, a common theme was found in the idea of "staff turnover." Many existing studies pointed to coworkers' perceptions of communication, helpfulness, and amount of respect as social factors that contributed to employee dissatisfaction. For example, in the work environment, few employees remain with the same employer for their entire work life. None of the studies compared communication, helpfulness, and respect based on whether or not a person had worked at more than one LTC facility. Therefore, once this gap in the literature was identified, a decision was made to expand on existing literature, by obtaining information that compared the two groups - one group with prior experience working in LTC facilities and one group with no prior LTC facility experience. In LTC facilities, nurses collaborate closely with social work professionals who have an ethical responsibility to honor the dignity and worth of all individuals. Part of their commitment is to "recognize the central importance of human relationships" (NASW 1996, p. 6). Multidisciplinary employees in LTC facilities care about human relationships. These human relationships occur within the environment and the aim is to include the whole environment thereby engaging in holistic practice (Ashford and LeCroy 2009). Thus, the following research questions that take into account the importance of all employees were formulated. 
The specific research questions were the following:

- Do employees who have prior experience working in long-term care environments report the same levels of satisfaction regarding communication with coworkers compared to employees who are working in long-term care for the first time?

- Is there a difference in staff's perception of helpfulness among employees who have prior long-term care experience and employees without long-term care experience?

- Is there a difference in staff's perception of respect for residents between employees with prior LTC work experience and employees with no prior LTC work experience?

- Is there a difference in staff's perception of respect for coworkers between employees with prior LTC work experience and employees with no prior LTC work experience?

\section{Methodology}

The study followed a descriptive cross-sectional design. The sampling frame included all employees of three LTC facilities. One facility was located in New Jersey and two facilities were located in South Carolina. All the facilities had interns who helped collect data. The facilities were similar in that all provided long-term care at the assisted living level and all were located in rural areas with a population of less than 50,000 people. Combined, the three facilities had a total of approximately 150 employees. The employees included administrators, nursing, and other non-professional staff. The facilities had a combined capacity for 215 residents. The capacity of the LTC facilities studied was less than the current national average of 104 licensed beds per facility (U.S. General Accounting Office 1999a, b). However, the states the facilities were located in were similar in composition regarding the average hours worked in a week. According to the Agency for Health Care Policy and Research (U.S. General Accounting Office 1999a), on an average weekly basis, $70.5 \%$ of employees in New Jersey LTC for profit facilities work $75 \%$ time or more while $16.2 \%$ of employees work $50 \%$ time or less (part-time workers). In South Carolina LTC for profit facilities, $72 \%$ are employees who work $75 \%$ time or more and $13.6 \%$ work less than $50 \%$ time (part-time workers). For clarification, when data from this study were collected, this information was the most current and useful information.

In all three facilities, where sampling for this study occurred, the majority of residents required minimal assistance in activities of daily living thereby demanding less of staff. Two of the facilities were private for profit environments and the other was a non-profit setting. Using an availability sampling technique, a survey research questionnaire collected information from employees who were present at staff meetings on the dates surveys were distributed.

\section{Sample}

The total sample included 119 employees. The sample was divided into two groups based upon employees' level of prior experience working in long-term care facilities. Group 1 had 70 employees with prior experience working in long-term care. Group 2 had 49 employees with no prior experience working in long-term care facilities. The two social work educators who created and validated the non-standardized survey discerned group membership after participants were surveyed.

A 12-item questionnaire was prepared for the survey. One section addressed demographic information such as age, education, gender, and race. The other section solicited information on employees' perceptions about working in the long-term care facility and interacting with residents, professional staff, and non-professional coworkers. After informed consents were obtained, the questionnaires were self-administered. Study participants were instructed to complete the questionnaire and then give it to the facility social worker or administrator.

Variables studied included work experience, satisfaction with communication, helpfulness of coworkers, and perceived respect. Prior experience was defined as having worked, previously in a different LTC facility. No prior experience was defined as this current position was the first time they had worked in long-term care with older adults. Definitions for satisfaction with coworker communication, helpfulness of coworkers, or respect shown by coworkers were not stipulated. Instead, satisfaction with coworker communication was based on participants choosing from a four-item scale that ranged from "all of the time" to "never". Study participants were asked to respond yes/no to one question that asked if they believed their coworkers were helpful. Respect was measured by two questions that asked participants to select "yes, no, or sometimes" to indicate if they perceived their coworkers (1) treated residents or (2) treated each other with respect.

The author created instrument that drew ideas for items from existing standardized instruments. For example, an item in a National Nursing Assistant Survey asked "how well they (nursing assistants) felt their training prepared them for the actual work." This survey also assessed via a single item "overall, how satisfied are you with your job." Interestingly, this single item job satisfaction measure was highly correlated to multiple item measures and research using the National Nursing Assistant Survey (Han et al. 2014).

\section{Data Analysis}

Data were analyzed using the statistical program for the social sciences (SPSS, version 11.0). Frequency distributions were calculated for demographic and work environment variables. 


\section{Results}

Table 1 shows that the majority of participants were White $(51.7 \%, n=60)$ females $(89.9 \%, n=107)$. Sixty-five percent $(n=76)$ were 36 years of age or older and $82.2 \%(n=95)$ had a high school education or greater.

For the entire group, communication satisfaction showed $57.8 \%(n=67)$ of subjects selected "most of the time". More participants did not feel staff was helpful $(54.6 \%, n=65)$ compared to those who believed staff was helpful ( $45.4 \%$, $n=54)$. Almost all participants stated that they believed their coworkers respected the residents $(96.6 \%, n=114)$ and their coworkers respected them $(82.1 \%, n=96)$.

To test four research questions, two groups were compared. Seventy participants (58.8\%) had worked previously in longterm care, before assuming their current position (group 1) while 49 (42.2\%) had not previously worked in long-term care (group 2). The first research question was "Do employees who have prior experience working in long-term care environments report the same levels of satisfaction regarding communication with coworkers compared to employees who are working long-term care for the first time?" With regard to satisfaction with communication with coworkers, group 1 selected most of the time more frequently $(61.8 \%, n=42)$ than group $2(52.1 \%, n=25)$ (see Table 2). A chi-square analysis was conducted between satisfaction with communication and

Table 1 Demographic information on LTC staff

\begin{tabular}{|c|c|c|}
\hline & Number & Percen \\
\hline \multicolumn{3}{|l|}{ Gender } \\
\hline Male & 12 & 10.1 \\
\hline Female & 107 & 89.9 \\
\hline \multicolumn{3}{|l|}{ Age } \\
\hline $18-25$ & 22 & 18.8 \\
\hline $26-35$ & 19 & 16.2 \\
\hline $36-45$ & 32 & 27.4 \\
\hline $46-55$ & 34 & 29.1 \\
\hline $56-65$ & 10 & 8.6 \\
\hline \multicolumn{3}{|l|}{ Race } \\
\hline White & 60 & 51.7 \\
\hline African American & 54 & 46.6 \\
\hline Latino/Mixed race & 2 & 1.8 \\
\hline \multicolumn{3}{|l|}{ Education } \\
\hline No high school & 1 & 0.8 \\
\hline Some high school & 21 & 17.9 \\
\hline Completed high school & 35 & 29.9 \\
\hline Some college & 32 & 27.4 \\
\hline College graduate & 28 & 24.0 \\
\hline
\end{tabular}

Percentages are based on cases for which there are valid data for a particular characteristic prior work experience $\left(X^{2}=1.53, p=.47\right)$, it was not statistically significant.

In relation to the second question, "Is there a difference in staff's perception of helpfulness among employees who have prior long-term care experience and employees without longterm care experience?", most participants did not feel their coworkers were helpful. There was virtually no difference between group $1(55.7 \%, n=39)$ and group $2(53.1 \%$, $n=26$ ), with both groups reporting that they felt their coworkers were not helpful. A chi-square analysis was conducted between helpfulness and prior work experience $\left(X^{2}=.08\right.$, $p=.78$ ), it was not statistically significant.

The third research question was "Is there a difference in staff's perception of respect for residents between employees with prior LTC work experience and employees with no prior LTC work experience?" The majority of participants in both groups believed that coworkers respected the residents all the time (97.1\% in group 1 and $95.8 \%$ in group 2). A chi-square analysis was conducted between perceived respect for residents and prior work experience $\left(X^{2}=.15, p=.70\right)$, it was not statistically significant.

The fourth research question was, "Is there a difference in staff's perception of respect for coworkers between employees with prior LTC work experience and employees with no prior LTC work experience?" A comparison of the two groups showed a slightly higher percentage of people in group 1 $(84.1 \%, n=58)$ who reported that they felt coworkers respected each other than did people in group $2(79.2 \%$,

Table 2 Work with elderly: people with prior experience and people with no prior experience

\begin{tabular}{|c|c|c|c|c|}
\hline & \multicolumn{2}{|c|}{ Prior experience $\left(70^{\mathrm{a}}\right)$} & \multicolumn{2}{|c|}{ No prior experience $\left(49^{\mathrm{a}}\right.$} \\
\hline & $N$ & $\%$ & $N$ & $\%$ \\
\hline \multicolumn{5}{|c|}{ Satisfaction with coworker communication } \\
\hline All of the time & 10 & 14.7 & 11 & 22.9 \\
\hline Most of the time & 42 & 61.8 & 25 & 52.1 \\
\hline Some of the time & 16 & 23.5 & 12 & 25.0 \\
\hline \multicolumn{5}{|l|}{ Helpful staff } \\
\hline Yes & 31 & 44.3 & 23 & 46.9 \\
\hline No & 39 & 55.7 & 26 & 53.1 \\
\hline \multicolumn{5}{|c|}{ Managers/staff respect residents } \\
\hline Yes & 68 & 97.1 & 46 & 95.8 \\
\hline No & - & - & - & - \\
\hline Some of the time & 2 & 2.9 & 2 & 4.2 \\
\hline \multicolumn{5}{|c|}{ Mangers/staff respect each other } \\
\hline Yes & 58 & 84.1 & 38 & 79.2 \\
\hline No & 6 & 8.7 & 6 & 12.5 \\
\hline Sometimes & 5 & 7.2 & 4 & 8.3 \\
\hline
\end{tabular}

${ }^{\mathrm{a}}$ Total N, however, percentages are based on cases for which there are valid data for a particular characteristic 
$n=38$ ). A chi-square analysis was conducted between respect for coworkers and prior work experience $\left(X^{2}=.53, p=.77\right)$, it was not statistically significant.

\section{Discussion, Implications, and Conclusions}

This study endeavored to learn how employees' work experience in long-term care would affect their perceptions and levels of respect and communication, and findings revealed that employees who had prior LTC experience perceived higher levels of respect toward residents and toward each other than those employees with no prior experience. As the older adult population ages, LTC facilities continue to be a growth industry in the USA (Maas and Buckwalter 2006; Sullivan 2016). Changing jobs is an inevitable aspect of growth and as this study found, the majority of participants were employees who had prior work experience in long-term care and were a part of this staff turnover. Prior LTC work experience provides a basis for comparison, and the research reveals how employees with prior LTC work experience may have been more discerning because they were slightly less satisfied all of the time with coworkers' communication than were those with no prior experience who stated satisfaction with their communication most of the time. However, the data also revealed that close to one in four participants with prior LTC experience were only satisfied with their coworkers' communication only some of the time, thereby indicating room for improvement in coworker communication existed. As already reported, communication among coworkers contributes to emotionally satisfying relationships for residents in LTC facilities (Sikorska-Simmons 2006). One way to enhance coworker communication is for administrators to create opportunities for employees to engage in team building efforts by assigning coworkers to teams and "helping team members focus on their priorities, while aligning their efforts with other disciplines" (Hansten and Washburn 1997, p. 72; Yates-Bolton 2010).

Helpfulness of coworkers contributes to a positive work environment. Unfortunately, the majority of participants in both groups did not believe their coworkers were helpful. Again, having prior LTC work experience provides a basis with which to compare one's current work experience. In this research, a single item measured helpfulness of coworkers. The item was part of a scale (Do you think this facility differs from other facilities you have worked at; more helpful staff, yes/no) designed to compare their experience in these facilities with their experience in other facilities. Only participants in group 1 had prior experience with which to make a personal comparison. Group 2 based their experience solely on the current work environment. Based on these facts, it appears that both groups were dissatisfied and therefore, something within the facilities may have affected perceptions. This is speculation as to whether the lack of helpfulness by coworkers could have stemmed from a lack of teamwork or individuals already having a heavy existing workload (Cohen-Mansfield 1997).

Another finding was employees with prior experience perceived higher levels of respect toward residents and toward each other than those employees with no prior experience. In other words, experienced employees may have learned valuable lessons about how to enhance their communication skills and garner respect based on that experience. As a result, exposure to normative service-related practices with older adults might both educate and sensitize workers to the needs of other workers and residents who work and live in LTC settings. Such experience appears to promote increased understanding and respect for the realities of people who are aging and the workers who care for them. In addition, the perceived respect present in facilities may result in staff retention because employees who feel they are treated with respect are more likely to stay in their current position rather than move to another position (Bonifazi 2000).

\section{Limitations}

Limitations in this study were related to the sample and the methodology. First, a non-probability available and convenient sample of employees at three LTC facilities in rural eastern portions of the USA was used. Consequently, the results are only representative of three particular LTC facilities. Staff in rural areas tends to be at risk of dual relationships because they know one another from their employment and from their social environment (Galbreath 2005). If dual relationships existed in the sample, this was unkown to the researchers and limited by collecting data from a small convenience sample. Nevertheless, the choice of a convenient availability sample allowed information to be obtained on the perceptions of everyone employed in the facilities, thereby reducing bias that may have been present had administrators identified staff that the questionnaires could be given to.

The second limitation was the use of cross-sectional survey research. Cross-sectional research designs capture a mere snapshot as information on study participants' perceptions is obtained at one point in time. Because perceptions can change from day to day and depend on the events occurring in a day, there may have been some events such as reprimands of employees or recent policy changes that may have influenced how the respondents answered the questions. Furthermore, the information was gathered in a questionnaire format, thus there was no opportunity to speak with participants and there was no knowledge of specific events at the facility that may have affected how the questionnaire was completed.

In the survey, no definitions for the concepts of helpfulness, communication, or respect for participants were provided. The first aim was to identify what the participants perceived on an individual level rather than have the participants fit our 
definitions. A second reason for not providing definitions stemmed from our inter-professional- professional and nonprofessional - staff approach to the working environment by including all employees of the LTC facilities. If definitions had been provided, employees might have had the capacity to identify or develop discipline specific definitions of the variables. For example, being asked if one ever helped a person clean trays off the dining room table would be helpful to participants from the dietary department, but would not be helpful to physical therapists or activity personnel. As a result, there was no capability to identify the idiosyncratic components of these variables.

\section{Directions for Future Research}

Findings from this research study suggest that communication among staff in long-term care facilities can be improved. New LTC employees ought to receive more education and be encouraged to participate in continuing education. Employees should also have a set educational requirement which includes a course on inter-professional practice and the importance of respectful coworker communication. The review of the literature revealed a degree of staff turnover occurs in some LTC facilities. The low state of nursing aide attitudes toward their job may help explain recruitment and retention problems; however, coworker relationships also play a pivotal role that strikes at the heart of human rights and social justice concerns. Social work has a double mandate of help and control and upholding social justice and dignity. This research examined three areas that could contribute to problems in job satisfaction and thus staff retention. A modicum of differences was found between those who had prior working experience and those who were working in LTC for the first time. Based on these findings, further research is required to clarify and elaborate on areas where problems exist regarding training, education, and supervision. Because the older adult population is growing, there is an increased future need for employees in LTC facilities, and more research would shed light on the working conditions in LTC facilities that require policy change. In the future, qualitative research could interview staff coworkers and have them explain their perceptions rather than select from a list of variables generated by researchers. Such studies could begin with the same variables examined in this study and then allow participants to verbally expand on aspects of communication, helpfulness, and respect among coworkers. Another way of measuring current job satisfaction would be to ask participants why they left their previous employment.

Throughout this research, LTC setting workers have been described in relation to how they perceive and receive communication and respect from their coworkers. Yet as described, more research is required to understand these complex relationships. Social workers engage in their occupation based on their ability to communicate with others and advocate for human rights and social justice. If social workers truly wish to maintain a holistic focus, then they need to consider everyone's perceptions that work in a long-term care environment. This study noted how respect and communication are vital to fostering positive coworker relationships and quality LTC facilities and that experience and training matters.

\section{References}

Ashford, J. B., \& LeCroy, C. W. (2009). Human behavior in the social environment: A multidimensional perspective (4th ed.). Belmont: Brooks/Cole, Cengage Learning.

Barbarotta, L. (2010). Voices from the field speak out about their passion for serving elders. Generations, 34(4), 43-52.

Blakemore, S. (2013). Patients' complaints not used to improve practice. Nursing Older People, 25(5), 5.

Bond, G. E., \& Fiedler, F. E. (1999). A comparison of leadership vs. renovation in changing staff values. Nursing Economics, 17(1), $37-50$.

Bonifazi, W. L. (2000). Up where they belong. Contemporary Long-term Care, 23(8), 22-27.

Bowman, B., \& Forbes, A. (2015). Addressing needs of long-term care facility residents during acute hospitalization. Medsurg Nursing, 24(6), 403-406.

Butler, R. N. (2002). Declaration of the rights of older persons. Gerontologist, 42(2), 152-153. https://doi.org/10.1093/geront/42.2. 152.

Cadogan, M. P., Franzi, C., Osterwell, D., \& Hill, T. (1999). Barriers to effective communication in skilled nursing facilities: differences in perceptions between nurses and physicians. Journal of the American Geriatrics Society, 47(71), 71-75.

Chu, C. H., Wodchis, W. P., \& McGilton, K. S. (2014). Turnover of regulated nurses in long-term care facilities. Journal of Nursing Management, 22(5), 553-562. https://doi.org/10.1111/jonm.12031.

Cohen-Mansfield, J. (1997). Turnover among nursing staff: a review. Nursing Management, 28(5), 59-63.

Colón-Emeric, C., Toles, M., Cary Jr., M. P., Batchelor-Murphy, M., Yap, T., Yuting, S., et al. (2016). Sustaining complex interventions in long-term care: a qualitative study of direct care staff and managers. Implementation Science, 11, 1-10. https://doi.org/10.1186/s13012016-0454-y.

DeBord, K., Canu, R. F., \& Kerpelman, J. (2000). Understanding a workfamily fit for single parents moving from welfare to work. Social Work, 45(4), 313-324.

Dilworth-Anderson, P., Pierre, G., \& Hilliard, T. S. (2012). Social justice, health disparities, and culture in the care of the elderly. Journal of Law, Medicine \& Ethics, 40(1), 26-32. https://doi.org/10.1111/j. 1748-720X.2012.00642.x.

Fulmer, T. (2016). Effective interdisciplinary teams: do we really know how to build them? Generations, 40(1), 64-70.

Galbreath, W. B. (2005). Dual relationships in rural communities. In N. Lohmann \& R. Lohmann (Eds.), Rural Social Work Practice (pp. 105-123). New York: Columbia University Press.

Han, K., Trinkoff, A. M., Storr, C. L., Lerner, N., Johantgen, M., \& Gartrell, K. (2014). Associations between state regulations, training length, perceived quality and job satisfaction among certified nursing assistants: cross-sectional secondary data analysis. International Journal of Nursing Studies, 51(8), 1135-1141. https://doi.org/10. 1016/j.ijnurstu.2013.12.008. 
Hansten, R., \& Washburn, M. (1997). Managerial rounds: getting in touch. (in hospital and nursing facilities). Nursing Management, 28(6), 72 .

Koenig, T. L., Lee, J. H., Fields, N. L., \& Macmillan, K. R. (2011). The role of the gerontological social worker in assisted living. Journal of Gerontological Social Work, 54(5), 494-510. https://doi.org/10. 1080/01634372.2011.576424.

Lockey, J. (1999). The low-down on pay and conditions. Nursing Homes, 1(4), 7-18.

Maas, M. L., \& Buckwalter, K. C. (2006). Providing quality care in assisted living facilities: recommendations for enhanced staffing and staff training. Journal of Gerontological Nursing, 32(11), 14 22.

McGilton, K. S., Boscart, V. M., Brown, M., \& Bowers, B. (2014). Making tradeoffs between the reasons to leave and reasons to stay employed in long-term care homes: perspectives of licensed nursing staff. International Journal of Nursing Studies, 51(6), 917-926. https://doi.org/10.1016/j.ijnurstu.2013.10.015.

National Association of Social Workers. (1996). Code of Ethics of the National Association of Social Workers. Washington: National Association of Social Workers.

Nilsson, A., \& Engstrom, M. (2015). E-assessment and an e-training program among elderly care staff lacking formal competence: results of a mixed-methods intervention study. BMC Health Services Research, 15(1), 1-11. https://doi.org/10.1186/s12913-015-0843-y.

Pope, E., Nel, E., \& Poggenpoel, M. (1998). The experience of registered nurses nursing in the general adult intensive care unit. A phenomenological qualitative research study. South African Journal of Nursing, 21(2), 32-38.

Rai, G. S. (2010). Burnout among long-term care staff. Administration in Social Work, 34(3), 225-240. https://doi.org/10.1080/03643107. 2010.480887
Rai, G. G. (2012). Organizational commitment among long-term care staff. Administration in Social Work, 36(1), 53-66. https://doi.org/ 10.1080/03643107.2010.550671.

Sikorska-Simmons, E. (2006). Linking resident satisfaction to staff perceptions of the work environment in assisted living: a multilevel analysis. The Gerontologist, 46, 590-598.

Squires, J. E., Hoben, M., Linklater, S., Carleton, H. L., Graham, N., \& Estabrooks, C. A. (2015). Job satisfaction among care aides in residential long-term care: a systematic review of contributing factors, both individual and organizational. Nursing Research \& Practice, 2015, 1-24. https://doi.org/10.1155/2015/157924.

Staub-Bernasconi, S. (2012). Human rights and their relevance for social work as theory and practice. In L. M. Healy \& R. J. Link (Eds.), Handbook of international social work: human rights, development, and the global profession (pp. 30-36). New York: Oxford University Press, Inc..

Sullivan, K. (2016). Workforce growth in community-based care: meeting the needs of an aging population. Monthly Labor Review, 1-15.

Tourangeau, A., Cranley, L., Spence Laschinger, H. K., \& Pachis, J. (2010). Relationships among leadership practices, work environments, staff communication and outcomes in long-term care A Tourangeau et al. relationships in long-term care. Journal of Nursing Management, 18(8), 1060-1072. https://doi.org/10.1111/j. 1365-2834.2010.01125.x.

U.S. General Accounting Office (1999a). Nursing homes: Complaint investigation processes often inadequate to protect residents. (Publication No. GAO/HEHS-99-80). Washington, DC: Author.

U.S. General Accounting Office (1999b). Nursing homes: Additional steps needed to strengthen enforcement of federal quality standards. (Publication No. GAO/HEHS-99-46). Washington, DC: Author.

Yates-Bolton, N. (2010). Human rights-based care for older people. Nursing Management-UK, 17(4), 26-27. 